\title{
Erratum to: American Society of Nuclear Cardiology and Society of Nuclear Medicine and Molecular Imaging Joint Position Statement on the Clinical Indications for Myocardial Perfusion PET
}

Timothy M. Bateman, MD (Co-Chair), ${ }^{a}$ Vasken Dilsizian, MD (Co-Chair), ${ }^{b}$ Rob S. Beanlands, MD, ${ }^{c}$ E. Gordon DePuey, MD, ${ }^{d}$ Gary V. Heller, MD, PhD, ${ }^{e}$ and David A. Wolinsky, $M D^{\mathrm{f}}$

a Mid America Heart Institute, University of Missouri - Kansas City School of Medicine, Kansas City, MO

b Department of Diagnostic Radiology and Nuclear Medicine, University of Maryland School of Medicine, Baltimore, MD

c Division of Cardiology, National Cardiac PET Centre, University of Ottawa Heart Institute, Ottawa, Canada

d Division of Nuclear Medicine, Department of Radiology, Mt. Sinai St. Luke's and Mt. Sinai West Hospitals, Icahn School of Medicine at Mt. Sinai, New York, NY

e Gagnon Cardiovascular Institute, Morristown Medical Center, Morristown, NJ

f Department of Cardiovascular Medicine, Cleveland Clinic Florida, Weston, FL

doi: $10.1007 / \mathrm{s} 12350-016-0716-8$

\section{ERRATUM TO: J NUCL CARDIOL 2016;23:1227-31 DOI 10.1007/S12350-016-0626-9}

Due to the Publisher's error, the above author names were omitted from the original article metadata. This erratum is being published to correct the scientific record, as well as the PubMed listing of the article. The author affiliations can be found below.

No wrongdoing or responsibility for this error lies with the authors, and the content of the article remains unchanged.

The online version of the original article can be found under doi:10.1007/s12350-016-0626-9.

Reprint requests: T. M. Bateman, MD, Mid America Heart Institute,

University of Missouri - Kansas City School of Medicine, 4320

Wornall Road, Suite 3000, Kansas City, MO 64111; tbateman@ saint-lukes.org

J Nucl Cardiol 2017;24:332.

$1071-3581 / \$ 34.00$

Copyright (c) 2016 American Society of Nuclear Cardiology. 